\title{
ELECTROLYTIC RECTIFICATION AND CATHODIC CHARGE REVERSIBILITY OF SOME VALVE METALS
}

\author{
C. K. DYER \\ Department of Metallurgy and Materials Science, University of Nottingham, Nottingham, U.K.
}

(Received April 2, 1974; in final form July 6, 1974)

\begin{abstract}
Optical studies and observations of electrode cathodic charge reversibility suggest a bulk rather than local effect in the electrolytic rectification behaviour of $\mathrm{Ti}$ and $\mathrm{Nb}$ electrodes. The proposed model involves reversible incorporation of hydrogen into the surface oxide films where it acts as a donor impurity. Applicability of the model to $\mathrm{Al}$ and $\mathrm{Zr}$ electrodes is discussed.
\end{abstract}

\section{INTRODUCTION}

The term "valve metals" for that group of elements, which includes $\mathrm{Ta}, \mathrm{Nb}, \mathrm{Zr}, \mathrm{Al}$, $\mathrm{Ti}$, Hf and $\mathrm{W}$, dates from an early research period which stressed the characteristic property of rectification of these oxide coated metals in most electrolytes (the forward direction is cathodic). Under reverse-bias, the anodic current flowing is generally due to growth of the surface oxide film by ionic transport. It is the fundamental difference in mechanism for the anodic and cathodic current that gives rise to the asymmetric current-voltage characteristics; the anodic current flow is only significant at high fields.

While the anodic film growth has been studied extensively and interpretation is at an advanced stage $^{1}$, cathodic behaviour has drawn a diversity of proposed mechanisms ${ }^{2}$ involving bulk or local effects from which it would appear that there is no single common cause of this phenomenon.

Recent studies ${ }^{3}$ of filmed $\mathrm{Nb}$ and Ti electrodes at optical frequencies during the passage of cathodic current add considerable support to the theory of electrolytic rectification based on rapid entry of hydrogen into the bulk oxide film. In the present work some dynamic current-voltage characteristics of filmed $\mathrm{Ti}, \mathrm{Nb}$ and $\mathrm{Al}$ electrodes are reported and interpreted in terms of reversible hydrogen incorporation.

\section{EXPERIMENTAL}

\subsection{Electrodes}

Spectroscopically pure $\mathrm{Ti}, \mathrm{Nb}$ and $\mathrm{Al}$ in the form of rods were used. Specimens were firstly anodised to ca. $100 \mathrm{~V}$, dried and sealed in "Araldite" epoxy resin. Sealed rods were then abraded to expose a cross section of metal $\left(0.039,0.71\right.$ and $1.92 \mathrm{~cm}^{2}$ for $\mathrm{Ti}$, $\mathrm{Nb}$ and $\mathrm{Al}$ respectively). $\mathrm{Ti}$ and $\mathrm{Nb}$ surfaces were polished on increasingly fine paper and, finally, with alumina paste (particle size, $5-30 \mathrm{~nm}$ ). Al electrodes were electropolished in perchloric acid/methanol (vol. ratio $1: 4)$.

Anodic films were grown galvanostatically at $10 \mathrm{~mA} / \mathrm{cm}^{2}$ in 1 wt. $\%$ ammonium hydrogen tetraborate solution made from Analar quality reagents and doubly distilled water.

Current-voltage characteristics were measured for initially polished and filmed $\mathrm{Ti}$ and $\mathrm{Nb}$ electrodes on immersion in a carbonate buffer solution $\left(0.1 \mathrm{MNaHCO}_{3}+0.1 \mathrm{MNa}_{2} \mathrm{CO}_{3}\right), \mathrm{pH}=9.7$. In this solution ellipsometric measurements verified that there was no detectable change in film thickness during the time of the experiments, and optical microscopy showed there were no local changes in interference colours of the films. Specimen potential was measured with respect to a calomel reference electrode and current supplied via a $\mathrm{Pt}$ counter electrode of large surface area $\left(\sim 10 \mathrm{~cm}^{2}\right)$. Aluminium electrodes were immersed in a standard BDH buffer solution, $\mathrm{pH}=7.0$ (in which corrosion of $\mathrm{Al}$ is minimal).

\subsection{Circuitry}

A continuous triangular voltage waveform (Prossor A101 generator) was superimposed via a potentiostat (Wenking $70 \mathrm{HC} / 3$, risetime $=3 \mu \mathrm{s}$ ) on to the working electrode (Figure 1). The current flowing through a resistor to the counter electrode was displayed 


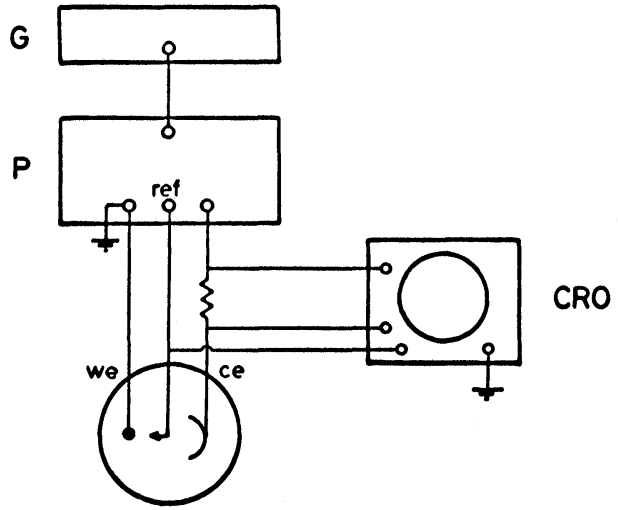

FIGURE 1 Block diagram: $G=$ Triangular waveform generator, $P=$ Potentiostat, $C R O=$ Cathode ray oscilloscope, $w e=$ working electrode, $c e=$ counter electrode, $\quad r e f=$ reference electrode.

vertically (after differential amplification) on an oscilloscope (Tektronix 502A) against a horizontal voltage deflection. Traces were recorded photographically.

\subsection{Procedure}

$\mathrm{Ti}$ and $\mathrm{Nb}$ electrodes were cycled between +3 and $-3 \mathrm{~V}$ or $+6 \mathrm{~V}$ and $-6 \mathrm{~V}$ (w.r.t. standard calomel electrode) at 1 or $10 \mathrm{kHz}$ and then at successively lower frequencies down to $0.1 \mathrm{~Hz}$ in some cases.

For significant asymmetric behaviour the A1 electrode was cycled between $+10 \mathrm{~V}$ and $-10 \mathrm{~V}$.

\section{RESULTS}

The dynamic current-voltage traces were highly asymmetric and were invariant with time or rapidly became so at each frequency. Reproducibility was dependent upon previous cycling history (see "Discussion").

The general behaviour of $\mathrm{Nb}$ and $\mathrm{Ti}$ electrodes, filmed or as-polished, is shown in Figure 2. In the cathodic-going half cycle non-linearly increasing currents are passed at low cathodic potentials (w.r.t. calomel electrode) but become nearly ohmic by $-3 \mathrm{~V}$. In the reverse direction (anodic-going) a negative resistance characteristic appears in the form of a current peak. At $1 \mathrm{~Hz}$ and below, filmed or polished $\mathrm{Ti}$ electrodes show a similar characteristic during the cathodic-going half cycle also (Figure 3 ).

In contrast, filmed A1 electrodes showed no

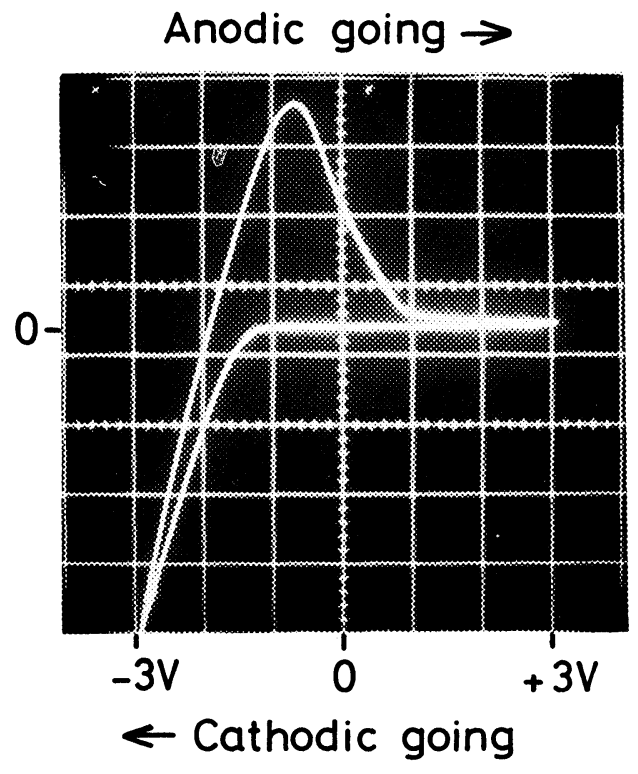

FIGURE 2 Current-voltage characteristic of an abraded Ti electrode $+3 \mathrm{~V}$ to $-3 \mathrm{~V}$ at $10 \mathrm{~Hz}$. Vertical scale: $2 \mathrm{~mA} /$ div., horizontal scale: $1 \mathrm{~V} /$ div.

current peaks in their dynamic current-voltage behaviour (Figure 4), but an increasing anodic current near the anodic voltage limit appeared after a few minutes of cycling at low frequencies $(0.1$ or $1 \mathrm{~Hz})$ and persisted at higher frequencies. A corrosion product was found to accumulate on the electrode surface.

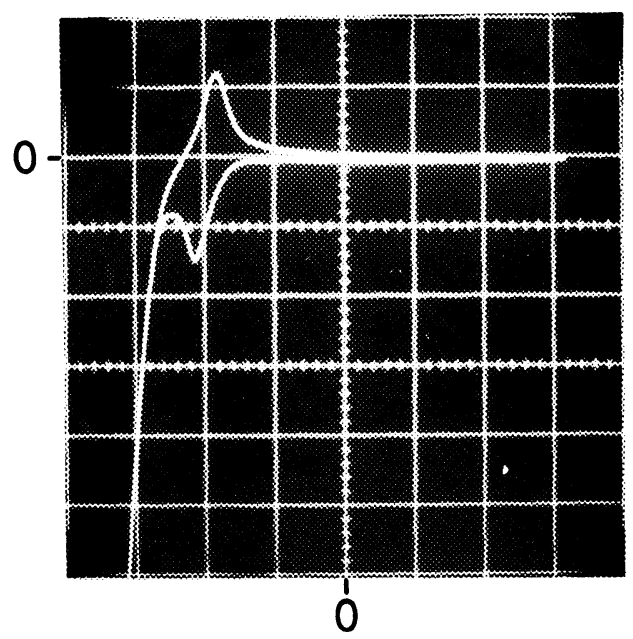

FIGURE 3 Abraded $\mathrm{Ti}$ electrode, $+3.1 \mathrm{~V}$ to $-3.1 \mathrm{~V}$, $0.1 \mathrm{~Hz}$. Vertical scale: $0.4 \mathrm{~mA} /$ div., horizontal scale: $1 \mathrm{~V} /$ div. 


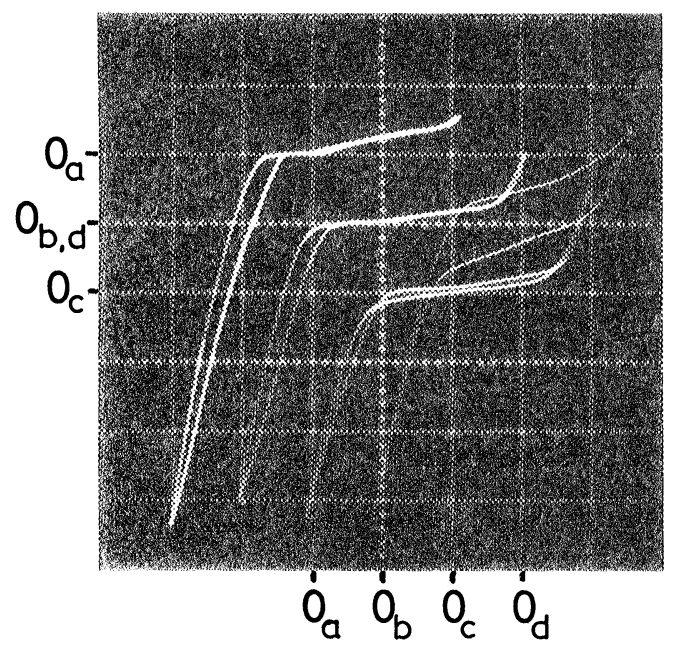

FIGURE 4 Aluminium electrode with $20 \mathrm{~V}$ anodic film, $+10 \mathrm{~V}$ to $-10 \mathrm{~V}$. Vertical scale: $10 \mathrm{~mA} /$ div., horizontal scale: $5 \mathrm{~V} /$ div. (a) $0.1 \mathrm{~Hz}$; (b) $1 \mathrm{~Hz}$; (c) $10 \mathrm{~Hz}$; (d) $100 \mathrm{~Hz}$.

The effect of increasing cycling frequency on $\mathrm{Ti}$ and $\mathrm{Nb}$ electrodes was to distort the current-voltage relationship (Figure 5) until it became indistinguishable at high frequencies, e.g. at $10 \mathrm{kHz}$ for $\mathrm{Ti}$ electrodes (Figure 6). $\mathrm{Nb}$ electrodes were less able to retain their low frequency characteristics which disappeared at $1 \mathrm{kHz}$. Filmed A1 electrodes showed similar "hysteresis" effects at $100 \mathrm{~Hz}$ and above (Figure 4).

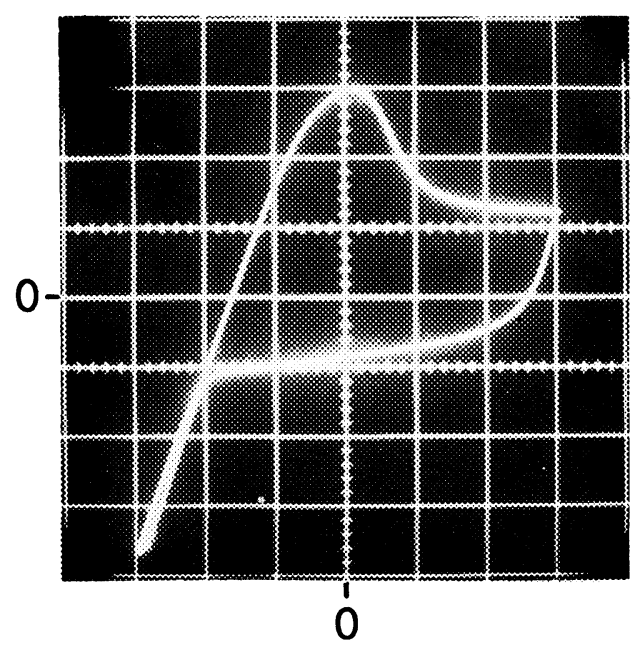

FIGURE 5 Abraded $\mathrm{Ti}$ electrode, $+3 \mathrm{~V}$ to $-3 \mathrm{~V}, 1 \mathrm{kHz}$. Vertical scale: $2.86 \mathrm{~mA} /$ div., horizontal scale: $1 \mathrm{~V} / \mathrm{div}$.

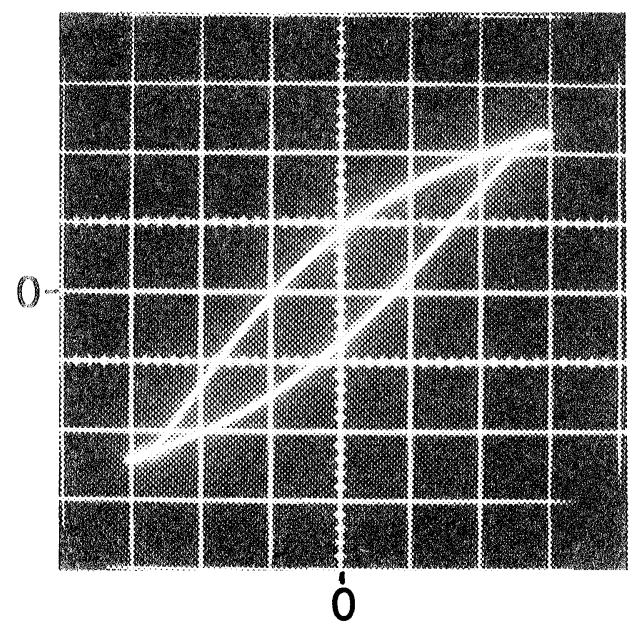

FIGURE 6 Abraded Ti electrode, $+3 \mathrm{~V}$ to $-3 \mathrm{~V}, 10 \mathrm{kHz}$. Vertical scale: $7.15 \mathrm{~mA} /$ div., horizontal scale: $1 \mathrm{~V} /$ div.

Increase in voltage amplitude (e.g. to $12 \mathrm{~V}$ peak to peak for $\mathrm{Ti}$ and $\mathrm{Nb}$ ) gave larger cathodic currents and anodic peaks but no new features appeared. For significant cathodic current flow, an increasing cathodic voltage (over-potential) with increasing frequency was required. This requirement was most marked for the filmed A1 electrode (Figure 4).

Charge flow behaviour was examined by measurement of the coulombic areas per cycle in the cathodic and anodic parts of the dynamic current-voltage traces. From this analysis (Tables I-III below) it is clear that while all electrodes show decreasing charge acceptance per cycle (cathodic and anodic) with increasing scan rate (or frequency) for a given amplitude, they each possess a different charge or discharge acceptance (at most frequencies) decreasing in the order: $\mathrm{Ti}, \mathrm{Nb}, \mathrm{Al}$ (despite the wider cycling limits used, filmed A1 still shows the lowest acceptances). The "reversibility" of charge acceptance as indicated by the magnitude of equal cathodic and anodic charges per cycle decreases in the same order, viz. Ti, $\mathrm{Nb}, \mathrm{A} 1$.

\section{DISCUSSION}

There is a considerable amount of evidence in support of weak spot theories of electrolytic rectification ${ }^{2,4}$. Theories based on microfissures in the anodic oxide film have been specifically rejected ${ }^{5}$ on the basis of experimental observations though it seems that 
locally, high conductivity effects due to impurity concentrations or structural changes could not be excluded. Electrolytic rectification is not believed to be a property of the film/electrolyte interface ${ }^{6,7}$.

In the presence of a metal rather than an electrolyte interface, rectification occurs in anodically grown films and $\mathrm{p}-\mathrm{n}$ or $\mathrm{p}-\mathrm{i}-\mathrm{n}$ junction theories seem to apply $5,6,8,9$.

A theory based on bulk changes in the anodic oxide film was proposed by Schmidt ${ }^{10,11}$, who suggested a hydrogen doping theory of electrolytic rectification for $\mathrm{Si}$ and $\mathrm{Ta}$ electrodes on the basis of experiments in protonic and aprotonic solutions. The theory is supported by previous observations of donor action in $\mathrm{ZnO}$ and evidence for field migration of interstitial hydrogen in $\mathrm{Pd}$ and the behaviour of protons in glass electrodes. Another theory involving bulk film properties was based on proton space charge effects to explain the capacitance changes but no conclusive evidence for the existence of a proton space charge was available ${ }^{12}$; also, a correlation between capacitance change and current flow was not found for anodized $\mathrm{Ta}$ electrodes in dilute $\mathrm{H}_{2} \mathrm{SO}_{4}$ solution.

With the aid of an automatic ellipsometer we have recently observed ${ }^{3}$ large and reversible changes in the optical absorption coefficient, $k$, in the complex anodic film refractive index $\bar{n}=n-i k$ during cathodic polarization of filmed $\mathrm{Ti}$ and $\mathrm{Nb}$ electrodes. Values of $k$ changed from 0 to $\sim 0.12$ reversibly and in the case of filmed $\mathrm{Ti}$, was accompanied by large changes in the real part of the film refractive index. Increase in $k$ was interpreted in terms of absorption by hydrogen dissolved in the oxide film where its ionization energy is substantially lower than that in the gaseous state. The additional effect of decrease $(\sim 15 \%$ max $)$ in refractive index of the surface films on $\mathrm{Ti}$ electrodes during cathodic polarization was explained by a change in electronic polarizability. The surface film is regarded as hydrated ${ }^{3}$ and a reversible reaction such as

$$
\mathrm{TiO}_{2} \cdot \mathrm{H}_{2} \mathrm{O}+\mathrm{H}^{+}+\mathrm{e}^{-} \rightleftharpoons \mathrm{Ti}(\mathrm{OH})_{3}
$$

is envisaged, which requires only protons and electrons to move. The conversion of $\mathrm{O}^{2-}$ to $\mathrm{OH}^{-}$is accompanied by a $\sim 20 \%$ decrease in electronic polarizability which by using the Lorentz-Lorentz relationship accounts for $\sim 90 \%$ of the measured maximum refractive index change. These observations were in accordance with large decreases in resistive and capacitive impedances measured over a wide response-time range (to $10 \mathrm{~ns}$ ) by a square wave technique, ${ }^{13}$ the use of which allowed separation of film, interfacial and other contributions to the overall electrode impedance under d.c. polarization conditions. Very high film conductivities were measured under cathodic polarization (films on Ti electrodes showed the highest values). Interpretation was in terms of entry of cathodically deposited hydrogen into the surface oxide film where it behaved as a donor impurity. While, of course, impedance changes cannot readily be used to distinguish between bulk and local effects in the oxide film the optical measurements strongly suggest a significant change in bulk properties. An alternative explanation for electrolytic rectification to those based on local effects of one sort or another can be envisaged with more confidence.

Accordingly, the present results can be interpreted in terms of a model involving dissolution of cathodically deposited hydrogen in the natural or anodically grown surface oxide film. Field migration followed by removal of hydrogen occurs during the anodic-going half cycle with the passing of anodic current. The anodic charge (per cycle) will generally be less than equal to the cathodic charge corresponding to the amount of hydrogen deposited per cycle, since at low frequencies some hydrogen will simply dissolve into the electrolyte or be lost in gaseous form. At and above a critical frequency, e.g. $10 \mathrm{~Hz}$ on Ti electrodes, the anodic and cathodic charges are approximately equal, and although this may not imply complete removal of all incorporated hydrogen in the film during the anodic-going half cycle, it shows that a good proportion is reversibly incorporated. The amount of this reversibly recoverable charge $\left(\sim 2 \mathrm{mC} / \mathrm{cm}^{2}\right)$ is larger (by approximately $100 x$ ) than could be accommodated on the surface of the film in view of its expected structure ${ }^{13,14,15}$, and supports the proposed model. Still more charge is recoverable anodically at lower frequencies but as a decreasing proportion of the cathodic charge with decreasing frequency. The high frequency limit of experiments on each electrode was set by charges that were largely capacitive (Figure 6).

The anodically recoverable charge on cycling $\mathrm{Nb}$ and A1 electrodes is still higher than could be accounted for by a surface effect. This occurs at lower frequencies than for Ti electrodes.

A net inflow of hydrogen during each cycle can accompany low frequency cycling if there is poor reversibility. For Ti electrodes this only occurs below $10 \mathrm{~Hz}$ but the corresponding limits for $\mathrm{Nb}$ and $\mathrm{A} 1$ are approximately $100 \mathrm{~Hz}$ and 0.1 to $1 \mathrm{kHz}$ respectively. A net inflow of hydrogen can give rise to hydride formation ${ }^{16}$ in the underlying metal substrate with 
accompanying expansion (up to $10 \%^{17}$ ) resulting in film cracking ${ }^{13}$. In the case of metals such as A1 which do not readily form hydrides, accumulation of hydrogen at the metal/oxide interface will cause blistering of the overlying film ${ }^{18}$. Such observations of film damage may have given rise to theories of electrolyte rectification based on microfissures. In previous work $^{13}$ we were careful to avoid this complication by using low current densities - verified by scanning electron microscopy. We found that a characteristic of cathodic polarization of cracked films was that of a high apparent film conductivity independent of film thickness in contrast to the behaviour of crack-free films, and suggested a dominant local effect. This effect was similar to that for electrodes filmed to $80 \mathrm{~V}$ where some tield recrystallisation of anodic oxide film on niobium had occurred ${ }^{\mathbf{1}}$; film conductivity, as measured at short times (or high frequencies) was nearly two orders of magnitude higher than expected, which was presumably due to higher electronic conductivity of the recrystallised region ${ }^{3}$.

Another effect of net inflow of hydrogen per cycle was the slow change of the current-voltage characteristic with time over the first few cycles such that both anodic and cathodic charges slowly increased as a result of increasing conductivity of the specimens. For this reason, the anodic and cathodic charges at

IABLE I

Coulombic charges during cycling of a titanium electrode

\begin{tabular}{|c|c|c|c|c|}
\hline \multirow[b]{2}{*}{$\mathrm{Hz}$} & \multicolumn{2}{|c|}{$\begin{array}{l}\text { ed surface: } \\
6 \text { V peak to peak } \\
\text { charge per cycle } \\
\left(\mathrm{mC} / \mathrm{cm}^{2}\right)\end{array}$} & \multicolumn{2}{|c|}{$\begin{array}{l}12 \mathrm{~V} \text { peak to peak } \\
\text { charge per cycle } \\
\left(\mathrm{mC} / \mathrm{cm}^{2}\right)\end{array}$} \\
\hline & Cathodic & Anodic & Cathodic & Anodic \\
\hline 0.1 & 38.4 & 5.84 & - & - \\
\hline 1 & 8.10 & 6.34 & - & ... \\
\hline 10 & 2.09 & 2.17 & 6.51 & 6.90 \\
\hline 100 & 0.298 & 0.298 & 0.805 & 0.852 \\
\hline 1000 & 0.0486 & 0.0468 & 0.0866 & 0.0984 \\
\hline 10,000 & 0.0121 & 0.0113 & & \\
\hline
\end{tabular}

b) Surface anodically filmed to $20 \mathrm{~V}$ (thickness $\sim 46 \mathrm{~nm}$ ): $6 \mathrm{~V}$ peak to peak $12 \mathrm{~V}$ peak to peak charge per cycle charge per cycle $\left(\mathrm{mC} / \mathrm{cm}^{2}\right) \quad\left(\mathrm{mC} / \mathrm{cm}^{2}\right)$

\begin{tabular}{cccccc}
\cline { 5 - 6 } Hz & Cathodic & Anodic & & Cathodic & Anodic \\
\hline 0.1 & 130 & 18.9 & - & \\
1 & 13.5 & 10.0 & 94.0 & 19.3 \\
10 & 2.12 & 2.0 & 7.82 & 7.74 \\
100 & 0.251 & 0.273 & 0.944 & 0.956 \\
1000 & 0.0333 & 0.0335 & 0.0921 & 0.109 \\
\hline
\end{tabular}

high cycling frequencies, though they may have been equal, were found to depend upon the net cathodic charge inflow history of the electrode.

It is more likely that irreversible formation of hydride or accumulation of gaseous hydrogen at the metal/oxide interface is the effect rather than the cause of low reversibility. $\mathrm{Ti}$, which shows the highest reversibility, is known readily to form a stable hydride $^{19}$. Reversibility seems to be related to the ease with which hydrogen enters the oxide film; the resulting increase in conductivity raises the rate of entry in an "auto-catalytic" manner. From Tables I to III it is evident that, except at $0.1 \mathrm{~Hz}$, the more reversible the electrode is, the larger the capacity for hydrogen uptake for a given frequency, amplitude and thickness of surface film (the naturally formed surface film on $\mathrm{Ti}$ and $\mathrm{Nb}$ electrodes after polishing is $\sim 5 \mathrm{~nm}^{20}$ ). The effect of greater film thickness is to dilute a given hydrogen concentration in the oxide, which lowers the conductivity, and thereby facilitates

TABLE II

Coulombic charges during cycling of a niobium electrode

\begin{tabular}{rlllll}
\hline a) Abraded surface: & $\begin{array}{l}\text { 6 V peak to peak } \\
\text { charge per cycle } \\
\left(\mathrm{mC} / \mathrm{cm}^{2}\right)\end{array}$ & & \multicolumn{2}{l}{$\begin{array}{l}\text { 12 V peak to peak } \\
\text { charge per cycle } \\
\left(\mathrm{mC} / \mathrm{cm}^{2}\right)\end{array}$} \\
\cline { 2 - 3 } \cline { 5 - 6 } $\mathrm{Hz}$ & Cathodic & Anodic & & Cathodic & Anodic \\
\hline 0.1 & 46.4 & 2.37 & & - \\
1 & 5.43 & 1.85 & & - & - \\
10 & 1.12 & 0.60 & & 0.966 & 0.557 \\
100 & 0.106 & 0.099 & & 0.106 & 0.107 \\
1000 & 0.0198 & 0.0204 & 0.0123 & 0.0140 \\
10,000 & 0.00267 & 0.00262 & & \\
\hline
\end{tabular}

b) Electrode anodically filmed to $60 \mathrm{~V}$ (thickness $\sim 138 \mathrm{~nm}$ ) $6 \mathrm{~V}$ peak to peak $12 \mathrm{~V}$ peak to peak charge per cycle charge per cycle $\left(\mathrm{mC} / \mathrm{cm}^{2}\right) \quad\left(\mathrm{mC} / \mathrm{cm}^{2}\right)$

\begin{tabular}{rlllll}
\cline { 5 - 6 } \cline { 5 - 6 } & Cathodic & Anodic & & Cathodic & Anodic \\
\hline 1 & 0.524 & 0.198 & - & - \\
10 & 0.309 & 0.191 & & - \\
100 & 0.0312 & 0.0315 & 0.108 & 0.072 \\
1000 & 0.00516 & 0.00486 & 0.00919 & 0.00971 \\
\hline
\end{tabular}

c) Electrode anodically filmed to $20 \mathrm{~V}$ (thickness $\sim 46 \mathrm{~nm}$ ): $6 \cdot V$ peak to peak charge per cycle $\left(\mathrm{mC} / \mathrm{cm}^{2}\right)$

$\begin{array}{rll}\mathrm{Hz} & \text { Cathodic } & \text { Anodic } \\ 100 & 0.0500 & 0.0630 \\ 1000 & 0.0095 & 0.0100\end{array}$


TABLE III

Coulombic charges during cycling of an aluminium electrode anodically filmed to $20 \mathrm{~V}(\sim 24 \mathrm{~nm}), 20 \mathrm{~V}$ peak to peak amplitude

\begin{tabular}{cll}
\hline & \multicolumn{2}{l}{ Charge per cycle $\left(\mathrm{mC} / \mathrm{cm}^{2}\right)$} \\
\cline { 2 - 3 } $\mathrm{Hz}$ & Cathodic & Anodic \\
\hline 0.1 & 36.5 & 7.10 \\
1 & 2.28 & 0.616 \\
10 & 0.167 & 0.0768 \\
100 & 0.0285 & 0.0197 \\
1000 & 0.0061 & 0.00692 \\
\hline
\end{tabular}

less, the entry of more hydrogen. Further inflow will then require a higher voltage amplitude. Anodic recovery of this diluted donor species will require a larger voltage excursion or longer time. The observed trends with increasing frequency (i.e. decreasing charge per cycle and increasing cathodic overvoltage) and increasing amplitude (i.e. increasing charges per cycle) are in accordance with this model, and are related to reversibility or the ease with which hydrogen enters the oxide film and is removed under reverse bias - dependences on thickness are less marked where there is high reversibility (Table I).

The cathodic current peak exhibited by Ti electrodes at low frequencies is a result of the reversible faradaic reaction occurring within the oxide film giving rise to a low film impedance. ${ }^{3,21}$ The reaction is dependent upon the electrochemical potential and involves reduction, by dissolved hydrogen, of $\mathrm{Ti}^{4+}$ to $\mathrm{Ti}^{3+}$ in the oxide film with accompanying optical changes ${ }^{3}$. The mechanism of high reversibility of the Ti electrode, as discussed above, may indeed be related to electrochemical reversibility. This may be additive but not necessarily causal (no electrochemical reactions in the oxide are present during cathodic polarization of filmed $\mathrm{Nb}$ electrodes $^{13}$ where the reversibility is reasonably high).

It is possible that the dielectric constant of the surface oxide films (which generally decreases in the order: $\mathrm{TiO}_{2}, \mathrm{Nb}_{2} \mathrm{O}_{5}, \mathrm{Al}_{2} \mathrm{O}_{3}$ ) makes charge separation easier for the hydrogen dissolved in the oxide ${ }^{3}$, with accompanying higher oxide conductivity (to allow more hydrogen deposition). There was certainly a large reduction in the ionization energy of hydrogen in these cathodically polarized films, since there was significant optical absorption at the longest wavelengths used, viz. $\sim 600 \mathrm{~nm}(h \nu \simeq 2 \mathrm{eV})$, and conductivity is high at room temperature $(k T \sim 0.026 \mathrm{eV})$.

\section{ZIRCONIUM ELECTRODES}

Similar observations may be made with other valve metals. Breen et al. ${ }^{18}$ proposed a hydrogen doping mechanism to explain the low impedance and current vs. potential hysteresis during cathodic polarization of anodically filmed $\mathrm{Zr}$ electrodes. In the same work $^{18}$ it was not found possible to establish whether hydrogen acted as a donor impurity in filmed $\mathrm{Al}$, owing to the constant cathodic potential condition under which they measured impedance and which rapidly caused film blistering with associated difficulty in measurement of its conductivity. Recently $^{22}$, the asymmetric conductivity of filmed $\mathrm{Zr}$ electrodes (to $40-75 \mathrm{~V}$ ) has been tentatively explained in terms of protonic migration along pores and cracks formed in films grown in nitric acid which consist of porous monoclinic zirconia. Other explanations offered were in terms of impurities or a property of the $\mathrm{ZrO}_{2}$ /electrolyte interface. Ontical measurements would clearly be useful in this case to establish whether a general hydrogen entry model is applicable. The magnitude of charge acceptance (and probably reversibility) is likely to be much less than for filmed $\mathrm{Nb}$ but more than for filmed $\mathrm{Al}^{18}$ since short time, electrode response measurements ${ }^{13}$ indicated a cathodic conductivity for filmed $\mathrm{Zr}$ electrodes at least an order of magnitude lower than for filmed $\mathrm{Nb}$ electrodes. The dielectric constant of zirconia is intermediate between anodic alumina and niobia at 12.5 .

\section{CONCLUSIONS}

While these observations of reversible charging do not exclude the possibility of additional high local conductivity, together with the optical studies showing a large bulk effect of hydrogen entry, they suggest that it is unlikely that "weak spots" are responsible for electrolytic rectification to any significant degree in the case of filmed $\mathrm{Ti}$ and $\mathrm{Nb}$ electrodes.

Optical studies of other valve metals should show whether this model involving general entry of hydrogen as a donor impurity has wider applicability, but conclusive results are only likely if the incorporation of hydrogen is reversible, and if massive substrate hydride formation or blistering which will otherwise obscure optical observations, are absent.

Charging reversibility is probably related to the ease of charge separation from hydrogen dissolved in the oxide films, and to the susceptibility to electrolytic rectification (as defined by the high frequency limit and voltage amplitude requirements). 


\section{ACKNOWLEDGEMENTS}

The author thanks the Science Research Council for financial support during the course of which this work was carried out, Prof. J. S. L. Leach for providing laboratory facilities and encouragement and $\mathrm{Mr} \mathrm{M}$. Walton for assistance with experimental equipment.

\section{REFERENCES}

1. J. W. Diggle (Ed.), Oxides and Oxide Films (Marcel Dekker Inc., New York, 1972)

2. Symposium on Electrolytic Rectification and Conduction Mechanisms in Anodic Films, Electrochemical Society, New York, 1967; L. Young, Anodic Oxide Films, (Academic Press, London, 1961) p. 141.

3. C. K. Dyer and J. S. L. Leach. To be published.

4. D. A. Vermilyea, J. Appl. Phys. 27, 963 (1956). N. Schwartz and M. Gresh, J. Electrochem. Soc. 110, 938 (1963). T. W. Hickmott, J. Electrochem. Soc. 113, 1223 (1966).

5. K. Hirata, H. Yoneyama and H. Tamura, Electrochim. Acta 17, 793 (1972).

6. Y. Sasaki, J. Phys. Chem. Solids 13, 177 (1960).

7. R. K. Nigam, R. S. Chaudhary and A. K. Batra, Electrochim. Acta 17, 2141 (1972).
8. W. Ch. Van Geel, Physica 17, 761 (1951); Halbleiterprobleme 1, 291 (1955).

9. Z. P. Zagorski and P. P. Panta, Electrochim. Acta 16, 1261 (1971).

10. P. F. Schmidt, J. Appl. Phys. 28. 278 (1957).

11. P. F. Schmidt, J. Electrochem. Soc. 107, 57C (1960).

12. D. A. Vermilyea, J. Electrochem. Soc. 115, 177 (1968).

13. C. K. Dyer and J. S. L. Leach, Electrochim. Acta 19, (1974), in press.

14. A. C. Zettlemoyer and E. McCafferty, Croatica Chemica Acta 45, 173 (1973).

15. H. P. Boehm, Discuss. Faraday Soc. 52, 264 (1971).

16. K. M. Mackay, Hydrogen Compounds of the Metallic Elements (E. and F. N. Spon Ltd., London, 1966).

17. D. G. Westlake, Trans. Met. Soc. A.I.M.E. 245, 287 (1969).

18. A. J. Breen, G. D. Fawkes, H. S. Isaacs, J. S. L. Leach and A. Y. Nehru, 3rd International Congress on Metallic Corrosion, M.I.R., Moscow 1969.

19. R. Otsuka, Sci. Pap. Inst. Phys. \& Chem. Res. 54, 97 (1960).

20. V. V. Andreeva, Akad. Nauk. S.S.S.R., Trudy Inst. Fiz. Khim., Vypusk VI Norye Metodi Fiziko-Khimicheskikh Issledovanii 2, Moscow (1957).

21. H. S. Isaacs and J. S. L. Leach, J. Electrochem. Soc. 110 , 680 (1963).

22. N. Ramasubramanian and T. Trottier, J. Electrochem. Soc. 119, 1375 (1972). 

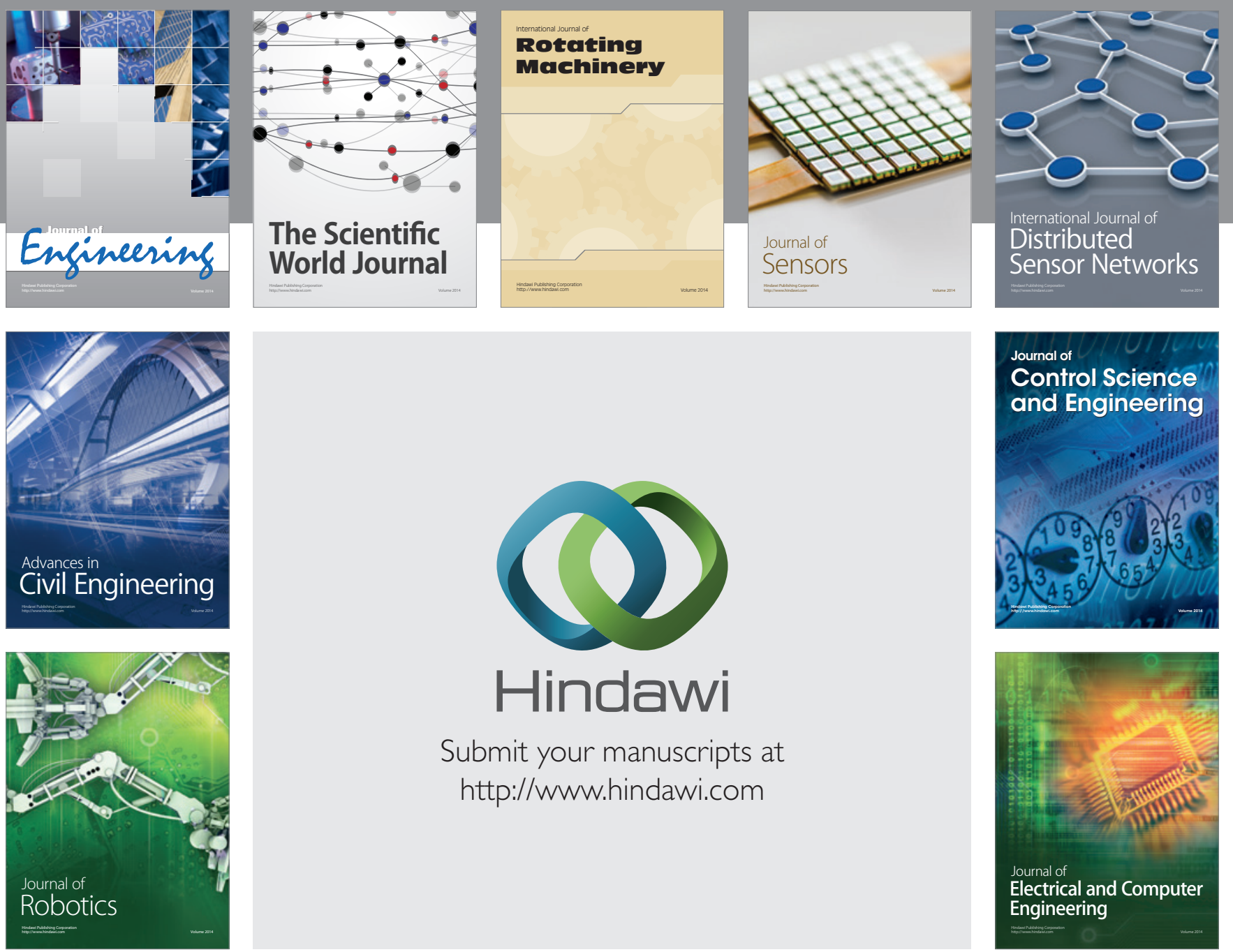

Submit your manuscripts at

http://www.hindawi.com
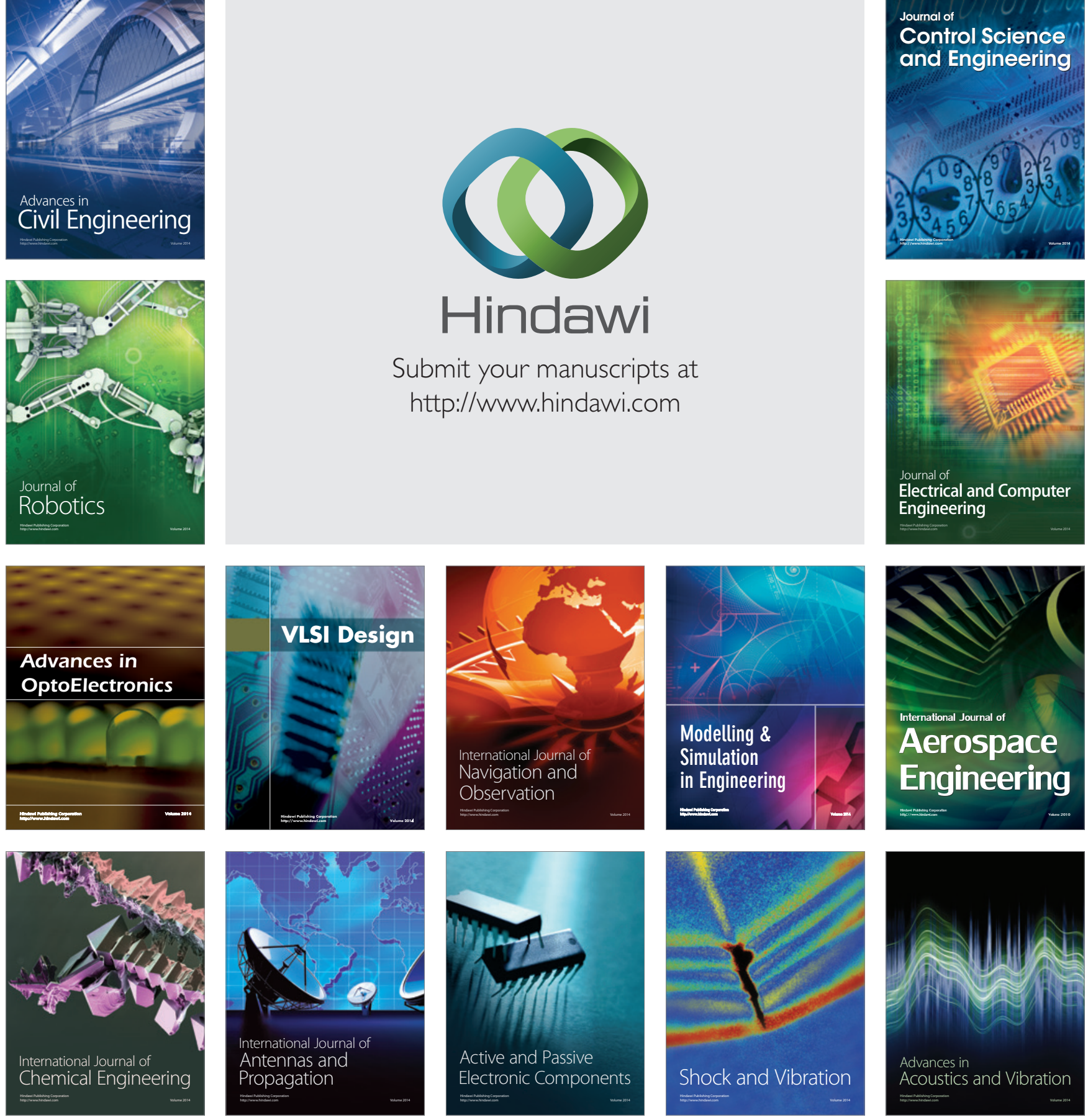